\title{
Broken doctor-patient relationships: why won't they listen?
}

\author{
Patient-doctor relationships may break down. We present and discuss a \\ hypothetical case
}

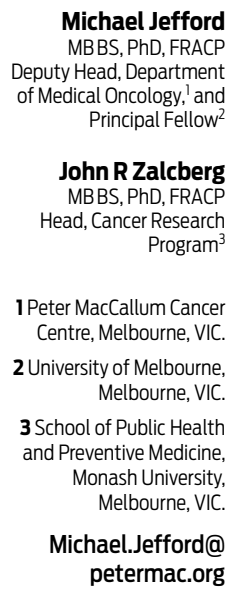

doi: 10.5694/mjal3.11211

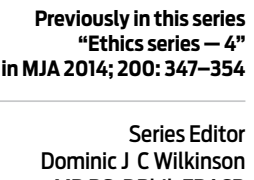

\section{Hypothetical case}

Deborah is a 47-year-old woman with metastatic breast cancer. Two years ago she was diagnosed with an earlystage breast cancer, treated with a wide local excision. She was advised to have postoperative adjuvant chemotherapy and radiotherapy, followed by hormonal therapy for 5 years.

Deborah is a single mother with two sons, aged 12 and 15 years, and works part-time as a cleaner. When first diagnosed, she was living in suburban Sydney. She returned to rural New South Wales 12 months ago to be closer to friends. She struggled with the chemotherapy and finished earlier than planned, receiving four of the planned six cycles. She completed all of the planned radiotherapy, although this was also difficult, as it involved a lot of travel. She was very fatigued throughout therapy and has experienced persisting side effects since completing therapy. Deborah was unable to work during her treatment and drew heavily on her savings. She has a good relationship with her sons, although they too have struggled with her illness, the treatments and the move to rural NSW.

Soon after her move, Deborah first met her current medical oncologist, a solo practitioner with a very busy practice. She described to him ongoing fatigue, sleep disturbance, fuzzy thinking and concerns about the cancer coming back. She indicated that she was not taking the recommended hormonal therapies because of side effects. The oncologist advised her to take the treatment to reduce the risk of the cancer returning. She left the consultations feeling that her concerns had not been heard or addressed. Deborah does not have a regular general practitioner. On advice from friends, she consulted a naturopath and attended an integrative health clinic. She was prescribed a range of therapies, which led to significant out-of-pocket expenses, and was encouraged to increase her exercise and join a support group.

Her relationship with the oncologist was not good. Her oncologist considered her to be difficult, whereas she felt patronised, dismissed and even ridiculed for using treatments that she believed were easing her symptoms. She did not attend a number of planned review appointments. The oncologist sent a letter advising that no more appointments would be arranged, and they had no further contact for 10 months.
Recently, Deborah returned to the oncologist. She had been experiencing persistent back pain. Her naturopath had tried a number of therapies and recommended a trial of yoga, but these were unhelpful. The naturopath advised her to consult the local medical clinic; plain x-rays were organised, and these indicated likely vertebral metastases. Following discussion with the oncologist, a computed tomography scan was done, showing metastases in several vertebrae but no evidence of visceral disease. The oncologist told her, rather bluntly, that she had incurable disease. She was shocked and angry. How could this be happening? Why couldn't it have been prevented or detected earlier? The oncologist reminded her that she had not attended a number of appointments and that she had ended the recommended adjuvant therapy prematurely. He strongly advised her to consider hormonal therapy to treat the recurrent disease, suggesting that the treatment would likely be effective.

$* * *$

Deborah is very fearful - about resuming treatment, about her future and her children's future. Her friends provide support, although they don't know the seriousness of her situation, and she continues to attend the naturopath and integrative health clinic. Over the next month, she has a further two meetings with the oncologist, which become heated as she feels that she is not being heard. She is worried about the proposed treatments and wonders "why bother" when the disease came back despite all the prior treatment. The oncologist is frustrated that she won't go ahead with treatment that is likely to be well tolerated and very likely to reduce symptoms, improve how she is feeling and extend survival. Concerned about lack of efficacy and possible treatment interactions, he tells her to stop the treatments recommended by the naturopath. This leads Deborah to abruptly end the consultation. To date, there has been no further contact and Deborah has not commenced any conventional medical therapies to treat her metastatic breast cancer.

\section{Discussion}

In this hypothetical case, it seems that the oncologist is frustrated that his patient does not attend appointments and, more importantly, does not follow his medical advice, apparently valuing the recommendations of her naturopath over and above his counsel, which he is 


\section{Key points to consider}

- Effective doctor-patient relationships are critical for high-quality patient-centred care.

- Key elements include respecting patient choice and autonomy, adopting a broad biopsychosocial perspective and sharing power and responsibility.

In adults with cancer, a range of patient, disease and treatment factors may increase the risk of psychosocial distress.

After completing treatment for cancer, people may experience a broad range of issues, including persisting side effects, psychological issues including fear of cancer recurrence, late and long-term effects, altered relationships, and practical consequences such as difficulty returning to work or study and loss of income.

- Chemotherapy is often recommended to women after surgical treatment of early-stage breast cancer, where it can increase the chance of cure. For people with metastatic breast cancer, chemotherapy can reduce symptoms, improve quality of life and extend survival.

- Identifying and responding to patient needs and concerns is critical to good care.

Patients may turn to complementary and alternative practices if they feel that conventional care is not addressing their needs and concerns.

- Health professionals may have legitimate concerns about complementary and alternative practices.

- Communication skills training can result in benefits for both patients and health professionals.

- The literature suggests patient and physician characteristics associated with difficult encounters.

- Medical associations, as well as insurance and indemnity organisations, provide guidance on ending doctor-patient relationships. as well as psychosocial distress has compromised the therapeutic relationship and led Deborah to seek out other practitioners and other means to address her concerns. If Deborah had a regular GP, that person might have been able to act as the coordinator of her treatment team, assisting with symptom and psychosocial management and enabling trust.

\section{Communicating about complementary medicine}

In Australia, use of complementary and alternative medicine (CAM) is common in people with cancer as well as in the general population..$^{6-8}$ Australian data suggest that people may look to CAM for a variety of reasons ${ }^{8}$ - as a new source of hope and a way to exercise control over their circumstances - and many experience CAM practitioners to be particularly supportive. Many people have a preference for natural therapies and perceive them to be non-toxic. Patients may feel helpless and that their needs are not adequately addressed by conventional medicine, or they may have incomplete trust in their doctors. ${ }^{9}$ Most patients do not discuss CAM use with their doctors. ${ }^{78}$

Health professionals frequently have concerns about people using CAM. They may worry that patients will forego therapies with proven efficacy. They may be concerned about safety or lack of efficacy of CAM, or potential interactions with standard therapies. Patients may be at risk of exploitation, encounter significant financial as well as opportunity costs, and be vulnerable to psychological risks, for example, if they are made to believe that treatments have not been effective because of insufficient effort or persistence.

The Peter MacCallum Cancer Centre has developed guidelines on how to effectively discuss CAM in a conventional oncology setting. ${ }^{10}$ Recommended steps include (i) eliciting the person's understanding of their situation and understanding their concerns and goals; (ii) respecting cultural and linguistic diversity and different belief systems; (iii) asking questions about CAM, including at critical points in the illness trajectory; (iv) exploring the patient's use of CAM and providing balanced evidence-based advice; (v) responding to their emotional state and supporting their desire for hope and control; (vi) discussing potential concerns about CAM; (vii) providing advice about CAM, which may be to encourage, accept or discourage the use of particular therapies, acknowledging the person's autonomy and right to self-determination; (viii) summarising the main points of the discussion; (ix) documenting the discussion; and $(x)$ monitoring. Based on these recommendations, communication skills training for clinicians has been developed. ${ }^{11}$ Communication skills training appears to improve the skills of health professionals ${ }^{12}$ and may lead to patient benefits including improved patient satisfaction and decreased distress. ${ }^{13}$ In our scenario, it is unknown whether the oncologist has attended communication skills training. This might include training in eliciting and responding to emotional cues, understanding patients' concerns, breaking bad news, discussing prognosis and discussing treatment options, including goals of care. Ideally, practitioners should receive feedback on their communication skills. 


\section{What can make a patient "difficult"?}

In the above case, the oncologist considers Deborah to be a difficult patient. Hinchey and Jackson have identified patient and physician characteristics associated with difficult encounters. ${ }^{14}$ Difficult patients were less likely to fully trust their doctor and were more likely to have five or more symptoms. They also had experienced recent stress and were more likely to have had a depressive or anxiety disorder. Physician characteristics included being less experienced and having poorer psychosocial orientation scores. ${ }^{14}$ Again, it seems possible that enhanced physician training together with greater attention to symptoms and psychosocial issues might alleviate some of the issues in difficult encounters.

\section{Approaching doctor-patient breakdown}

There are a number of means by which the doctor-patient relationships might end in the general practice setting. ${ }^{15}$ This may be through mutual agreement that the relationship has not worked as hoped; confrontation, perhaps when one party wishes for the relationship to end but the other disagrees; the "fade-out" where patients decide not to return; the "hand-off" when a practitioner refers the patient with the purpose of ending the relationship; and the "put-off" when a practitioner refuses to accede to patient demands so that the patient loses patience and consults another doctor. The relationship ends with "breakdown", when one party decides that the other has acted in a way that conflicts with the other's expectations, and subsequent "termination". Roberson Barnard has recently described the circumstance and process around firing her own oncologist. ${ }^{16}$

Many medical associations, as well as insurance and indemnity organisations, provide guidance regarding the ending of patient-physician relationships. Common steps include (i) documenting reasons for terminating the relationship; (ii) providing the patient with written advice of the intention to terminate the relationship, including some explanation of the reason; (iii) agreeing to provide care for a reasonable period of time, to allow the person sufficient time to identify another doctor; (iv) assisting the person to find another doctor, referring patients to lists of practitioners; and (v) offering to transfer records to the new provider.

So what should the oncologist and patient do at this point? With the opportunity to reflect on the past 12 months, both may realise that the current situation was not only potentially avoidable but theoretically may be dealt with by both the patient and doctor clarifying their expectations and learning to consider a mutually respectful relationship. While this approach at rapprochement may not prove particularly successful, leaving the patient without any access to specialist oncological skills in a small rural community is not an acceptable option clinically. Either the doctor needs to provide realistic suggestions as to how the patient can be managed by another practitioner or both parties need to make the effort to work together as the patient adjusts to her diagnosis and circumstances and the doctor accepts that, in this case, he is but one member of the patient's team.

\section{Competing interests: No relevant disclosures.}

Provenance: Commissioned; externally peer reviewed.

1 Bergh J, Jönsson PE, Glimelius B, et al. A systematic overview of chemotherapy effects in breast cancer. Acta Oncol 2001; 40: 253-281.

2 National Breast Cancer Centre and National Cancer Control Initiative. Clinical practice guidelines for the psychosocial care of adults with cancer. Sydney: National Breast Cancer Centre, 2003. https://www.nhmrc.gov. au/files_nhmrc/publications/attachments/cp90_psychosocial_care_ adults_cancer_131223.pdf (accessed Jul 2014).

3 Brennan M, Butow P, Spillane A, Boyle F. Survivorship care after breast cancer. Aust Fam Physician 2008; 37: 826-830.

4 Jefford M. Improving outcomes for cancer survivors in Australia. Cancer Forum 2009; 33: 159-163. http://www.cancerforum.org.au/Issues/2009/ November/Forum/Overview_Improving_outcomes_for_cancer_survivors_ in_Australia.htm (accessed Jul 2014).

5 Mead N, Bower P. Patient-centredness: a conceptual framework and review of the empirical literature. Soc Sci Med 2000; 51: 1087-1110.

6 Ernst E, Cassileth BR. The prevalence of complementary/alternative medicine in cancer: a systematic review. Cancer 1998; 83: 777-782.

7 MacLennan AH, Wilson DH, Taylor AW. The escalating cost and prevalence of alternative medicine. Prev Med 2002; 35: 166-173.

8 Begbie SD, Kerestes ZL, Bell DR. Patterns of alternative medicine use by cancer patients. Med J Aust 1996; 165: 545-548.

9 Patterson RE, Neuhouser ML, Hedderson MM, et al. Types of alternative medicine used by patients with breast, colon, or prostate cancer: predictors, motives, and costs. J Altern Complement Med 2002; 8: 477-485.

10 Schofield P, Diggens J, Charleson C, et al. Effectively discussing complementary and alternative medicine in a conventional oncology setting: communication recommendations for clinicians. Patient Educ Couns 2010; 79: 143-151.

11 Schofield P, Diggens J, Hegarty S, et al. Discussing unproven therapies. In: Kissane DW, Bultz BD, Butow PM, Finlay IG, editors. Handbook of communication in oncology and palliative care. New York: Oxford University Press, 2011.

12 Fellowes D, Wilkinson S, Moore P. Communication skills training for health care professionals working with cancer patients, their families and/or carers. Cochrane Database Syst Rev 2004; (2): CD003751.

13 Uitterhoeve RJ, Bensing JM, Grol RP, et al. The effect of communication skills training on patient outcomes in cancer care: a systematic review of the literature. Eur J Cancer Care (Engl) 2010; 19: 442-457.

14 Hinchey SA, Jackson JL. A cohort study assessing difficult patient encounters in a walk-in primary care clinic, predictors and outcomes. J Gen Intern Med 2011; 26: 588-594.

15 Stokes T, Dixon-Woods M, McKinley RK. Ending the doctor-patient relationship in general practice: a proposed model. Fam Pract 2004; 21: 507-514.

16 Roberson Barnard S. Is It OK to fire my oncologist? J Oncol Pract 2014; 10: $151-153$ 